\title{
Typing class I HLA-A gene using a nested PCR-RFLP procedure
}

E.C. Castelli ${ }^{1}$, D.S. Gil ${ }^{1}$,

L.C.S. Veiga ${ }^{2}$ and J.L.V. de Camargo ${ }^{1}$
${ }^{1}$ TOXICAN, Departamento de Patologia, Faculdade de Medicina, Universidade Estadual Paulista, Botucatu, SP, Brasil

${ }^{2}$ Departamento de Genética, Faculdade de Medicina de Ribeirão Preto, Universidade de São Paulo, Ribeirão Preto, SP, Brasil

\section{Correspondence}

E.C. Castelli

TOXICAN

Departamento de Patologia

FMB, UNESP

18618-000 Botucatu, SP

Brasil

E-mail: erickcastelli@terra.com.br

Research supported by FAPESP

(Nos. 01/08139-0 and 01/9448-7),

and CNPq (No. 302361/2003-0).

Received April 30, 2004 Accepted February 10, 2005 ....................

\begin{abstract}
In order to detect several new HLA-A class I alleles that have been described since 1998, the original PCR-RFLP method developed to identify the 78 alleles recognized at that time at high resolution level was adapted by us for low and medium resolution levels using a nested PCR-RFLP approach. The results obtained from blood samples of 23 subjects using both the PCR-RFLP method and a commercial kit (MicroSSP1A ${ }^{\circledR}$, One Lambda Inc.) showed an agreement higher than $95 \%$. The PCR-RFLP adapted method was effective in low and medium resolution histocompatibility evaluations.
\end{abstract}

Key words

- Human leukocyte antigen-A

- HLA-A

- Typing

- RFLP

- Polymorphism

- Major histocompatibility complex
The human major histocompatibility complex, also known as the human leukocyte antigen (HLA) complex, is a 4-Mb highdensity and polymorphic region located at 6 p21.3 with more than 200 genes and which represents about $2.5 \%$ of the human chromosome 6 . These genes belong to three main groups, class I, II and III, which are structurally and functionally different (1-3). The HLA class I molecules are glycoproteins expressed in almost all nucleated cells that collect intracellular peptide fragments and transport them to the cell surface, where the HLA-peptide combination is presented to $\mathrm{CD} 8+\mathrm{T}$ cells. Class II molecules are expressed in antigen-presenting cells such as B lymphocytes and dendritic cells, and present peptides to $\mathrm{CD} 4+\mathrm{T}$ cells. Class III genes encode soluble proteins of the complement system and cytokines like tumor necrosis factor (TNA- $\alpha$ and LTA- $\alpha$ ) (1-3).

High polymorphism is an important characteristic of the HLA complex. By Septem- ber 2004, 1114 alleles had been described for class I genes: 325 for HLA-A, 592 for HLA-B, 175 for HLA-C, 6 for HLA-E, 2 for HLA-F, and 15 for HLA-G. For class II, 707 alleles had been described: 3 for DRA, 458 for DRB, 28 for DQA1, 56 for DQB1, 20 for DPA1, 110 for DPB1, 4 for DMA, 6 for DMB, 8 for DOA, and 8 for DOB (4; http:// www.ebi.ac.uk/imgt/hla/stats.html). The compatibility of these polymorphisms between transplant recipients and organ donors is necessary for graft acceptance and, therefore, detailed histocompatibility evaluation is required to reduce or avoid tissue rejection (5).

The homology among class I genes is a limiting factor for several HLA typing methods and justifies molecular instead of serological approaches (6). Sequence-based methods involving sequence-specific primers (68 ), sequence-specific oligonucleotide probes (9) and sequencing-based techniques (10) are powerful tools used to assign HLA poly- 
morphisms. Their specific uses depend on individual case needs, resolution level, the number of analyses to be performed, and available funds. Laboratories that do not have sequencing facilities or sufficient financial support for expensive kits may benefit from alternative tools for HLA typing.

We present here an alternative procedure for HLA-A polymorphism assignment based on a PCR-RFLP methodology originally used by Mitsunaga et al. (11) to analyze 78 HLAA class I alleles. In order to validate this alternative procedure at low (allele family) and medium (allele family/allele) resolution levels, the present study was carried out to detect all of the 274 alleles described in the literature up to January 2003 (12). The Hospital Ethics Committee at this Medical School approved this study protocol.

A nested PCR approach with generic primers was the first step for specific amplification of exons 2 and 3, where the polymorphisms within the HLA class I genes are mainly located. However, due to the great similarity of class I genes and the presence of pseudogenes in the HLA complex, the PCR primer used in the original RFLP methodology (11), ASP5 - GCCCCGAACCCTCSTC CTGCTA/ASP3 - CCGTGGCCCCTGGT ACCCGT, frequently also amplify other class I genes. The HLA-B and -C loci have only one or two mismatches in the region of the original ASP5, depending on the polymorphism of each individual. As a consequence, these loci usually provide PCR products of the same size (not distinguished by common electrophoresis) and provide the same RFLP patterns for most endonucleases applied, confusing the analysis.

Therefore, a new forward primer (ASPTBE) with 3 terminal mismatches was developed in our laboratory to be used with the original ASP3 primer. Initially, amplification of genomic DNA with generic primers (ASPTBE, CAGACSCCGAGGATGG CC/ASP3 - CCGTGGCCCCTGGTACCC GT) was performed to obtain a 1017-bp sequence including exon 1 to intron 3 of the HLA-A gene. This PCR product was diluted 1:1000 in TE buffer (10 mM Tris-HCl, $\mathrm{pH}$ 7.5 , and 1 mM EDTA) and used as template for two further PCR procedures to amplify separately exon 2 (NA23 - GKCCTCGCTCT GGTTGTAGTAGC/NA25 - CAGGCTCY CACTCCATGAGGTATTTC primers) (11) and exon 3 (NA33 - CGTCTCCTTCCCGTT CTCCAGGT/NA35 - GTCSGGGCCAGGT TCTCACAC primers) (11). DMSO was included in all reactions to increase PCR specificity. Restriction analyses were performed for exons 2 and 3 with endonucleases that were chosen on the basis of the resolution level needed (see below).

In order to obtain a low resolution level, the PCR-RFLP methodology was adapted to permit the separate evaluation of each HLAA allele family. After amplification of exons 2 and 3, RFLP analyses were performed. Endonucleases Bsp 1286I, BsrI, Bst NI, M $n l \mathrm{I}$, HinfI, MspI, SacII, and PstI were used for exon 2, and endonucleases BslI, Fnu4HI, BsrI, Bsp1286I, HaeIII, NlaIII, HhaI, and MspI were used for exon 3, for a total of 16 RFLP analyses (with 13 different endonucleases). Tables with the RFLP patterns for each allele family are available from the corresponding author.

To obtain a level of medium resolution, the endonucleases originally proposed (11), $B s a \mathrm{JI}, B s p 1286 \mathrm{I}, B s r \mathrm{I}, B s t \mathrm{NI}, H i n \mathrm{fI}, M s p \mathrm{I}$, $M n l I$, and SacII for exon 2, and BsaAI, BslI, BsoFI, Bsp1286I, BsrI, HaeIII, HgaI, HhaI, MspI, MnlI, and NlaIII for exon 3, are not suitable because they do not permit the detection of the recently described and specific high frequency HLA-A alleles. Therefore, other restriction endonucleases were added in order to increase the resolution and/or to facilitate the detection of heterozygous combinations. For exon 2 analysis, 12 enzymes were added: PstI and NlaIV for standard digestion and TspRI, AvaII, BslI, HhaI, NlaIII, $H g a \mathrm{I}$, BsaHI, HaeIII, FokI, and HphI for additional digestion. For exon 3, seven en- 
donucleases were added: TspRI and NlaIV for standard digestion and MspA1, BsaJI, $B s t \mathrm{NI}, \mathrm{Sac} \mathrm{II}$, and $H p h \mathrm{I}$ for additional digestion. The RFLP pattern for each HLA-A allele and the endonucleases proposed for the medium resolution level are available in PDF format (contact the corresponding author). Currently, 325 alleles for the HLA-A locus are known (4) and new ones are expected to be continuously described; all of these new alleles can be adequately inserted into the technical flowchart presented.

The procedure is as follows: genomic DNA was obtained using the GFX ${ }^{\circledR}$ Genomic Blood DNA Purification kit (Amersham Pharmacia Biotech Inc., Piscataway, NJ, USA) following manufacturer recommendations. The genomic DNA was amplified by PCR using the ASPTBE/ASP3 primers. PCR was performed in a final volume of 20 $\mu 1$ containing $4 \%$ DMSO, $0.3 \mathrm{mM}$ of each dNTP, $2.0 \mathrm{mM}$ magnesium chloride, 0.30 $\mu \mathrm{M}$ of each primer, and 1 unit of DNA polymerase (Invitrogen Corporation, Carlsbad, CA, USA). The mixture was heated to $94^{\circ} \mathrm{C}$ for $6 \mathrm{~min}$ for DNA denaturation followed by 34 cycles of $94^{\circ} \mathrm{C}(1 \mathrm{~min}), 64^{\circ} \mathrm{C}(1$ $\mathrm{min})$, and $72^{\circ} \mathrm{C}(1 \mathrm{~min})$ each. An $8-\mu 1$ aliquot of each reaction was checked on $2 \%$ agarose gel stained with ethidium bromide. The PCR product was diluted in TE buffer or ultrapure water at 1:1000 and used as template (usually $2 \mu \mathrm{l})$ to amplify the HLA-A gene exons 2 (NA23/NA25) and 3 (NA33/NA35). Reactions for exons 2 and 3 were performed in $100 \mu \mathrm{l}$ and $120 \mu \mathrm{l}$ final volumes, respectively, containing $3.5 \%$ DMSO, $0.25 \mathrm{mM}$ of each dNTP, $2.0 \mathrm{mM}$ magnesium chloride, $0.30 \mu \mathrm{M}$ of each primer, and 1.5 unit of DNA polymerase (Invitrogen). The reaction mixtures were heated to $64^{\circ} \mathrm{C}$ for $3 \mathrm{~min}$ for DNA denaturation followed by 34 cycles of $94^{\circ} \mathrm{C}(1 \mathrm{~min}), 65^{\circ} \mathrm{C}(1 \mathrm{~min})$, and $72^{\circ} \mathrm{C}(1$ $\mathrm{min}$ ) each. After the reaction, $5 \mu \mathrm{l}$ of each reaction mixture was checked on $2 \%$ agarose gel stained with ethidium bromide.

Aliquots of $7 \mu \mathrm{l}$ of each PCR product were digested with the restriction endonucleases used for the medium resolution level according to supplier recommendations. The cleavage products were subjected to $7 \%$ polyacrylamide gel electrophoresis stained with silver nitrate (Figure 1). The fragment patterns generated by the RFLP procedures were compared using an RAS software (RFLP Analysis System) developed in our laboratory. This software is free with a controlled distribution that uses a database containing all of the patterns of HLA-A allele for each endonuclease proposed in order to calculate which allele may be present in a specific sample. Profiles for HLA-A and HLA-G are currently available (contact the corresponding author).

The PCR-RFLP approach at the low resolution level was able to discriminate amongst all allele families and, in a few cases, a specific allele. This typing tool could be very useful for screening the distribution tendencies of HLA-A antigens in diseases. At the medium resolution level the updated nested PCR-RFLP approach permitted the discrimination of heterozygous or homozygous HLAA allele family combinations with a small group of alleles each, and in some cases, specific alleles.

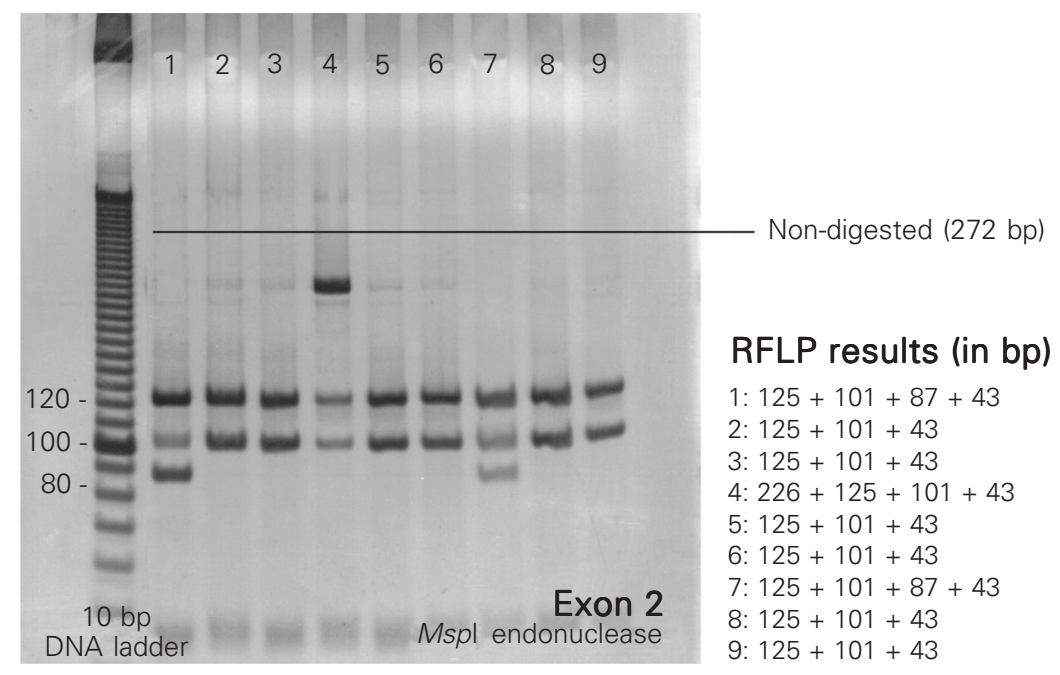

Figure 1. Restriction fragment length polymorphism (RFLP) banding patterns of HLA-A exon 2 digested with endonuclease Mspl (lanes 1-9). The results (in bp) are indicated on the right side ( $7 \%$ polyacrylamide gel stained with silver nitrate) 
To test the efficiency of the nested PCRRFLP methodology at a medium resolution level, DNA from blood samples of 23 volunteers was evaluated using the proposed method and a commercial kit (MicroSSP1A ${ }^{\circledR}$, One Lambda Inc., Canoga Park, CA, USA), widely employed in histocompatibility tests for organ transplantation. All analyses per- formed using the nested PCR-RFLP methodology and the commercial kit were compatible, assigning either homozygous or heterozygous combinations (Table 1). Two evaluations using the commercial kit did not detect one of the alleles, probably due to the use of samples under conditions which differed from the kit recommendations, leading

Table 1. Comparison between nested PCR-RFLP and a commercial kit (MicroSSP1A ${ }^{\circledR}$ ): results of 23 blood samples from normal subjects. The results of the analyses agreed, except for 2 cases for which only one allele family was detected by the commercial kit (weak amplification probably due to low quality DNA).

\begin{tabular}{|c|c|}
\hline PCR-RFLP TYPING & MICROSSP1A® TYPING \\
\hline 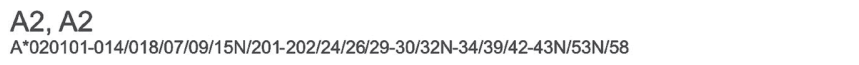 & $\begin{array}{l}\text { A2, A2 } \\
\text { All A2 alleles except } A^{*} 021701, A^{*} 021702 \text { and } A^{*} 0250\end{array}$ \\
\hline $\begin{array}{l}\text { A32, A74 } \\
A^{*} 3201 / 03-07, A^{*} 7401-03 / 05 / 07-08\end{array}$ & $\mathrm{~A} 32, \mathrm{~A} 74$ \\
\hline $\begin{array}{l}\text { A24, A29 } \\
\text { A }^{*} 2402101-0202 / 0301-0302 / 05 / 09 N / 11 N / 20 / 21 / 25 / 26 / 29 / 32-34 / 36 N, A^{*} 2902-04 / 06\end{array}$ & $\begin{array}{l}\text { A24, A29 } \\
\text { A*29010101-06, A*24020101-022/04-05/08-09N/11N-13/15-17/20-21/23/25-31/32/34 }\end{array}$ \\
\hline $\begin{array}{l}\text { A1, A2 } \\
{\text { A } 010101-0102 / 03-06 / 09, A^{*} 020101-0104 / 0108 / 07 / 09 / 12-13 / 15 N / 201-202 / 24 / 26-27 / 29-30 / 32 N-33 / 42-}^{43 N / 49 / 53 N / 55}\end{array}$ & 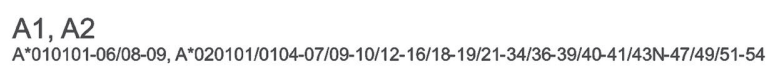 \\
\hline $\begin{array}{l}\text { A2, A29 } \\
\text { A }^{*} 020101, A^{*} 2902 / 04 / 06\end{array}$ & $\begin{array}{l}\text { A2, A29 } \\
\text { A }^{*} 020101 / 0104-07 / 09-10 / 12-16 / 18 / 21-34 / 36-38 / 40-41 / 43 N-47 / 49 / 51-54, A^{*} 29010101-06\end{array}$ \\
\hline $\begin{array}{l}\text { A26, A29 } \\
\text { A*2601-02/05/08/10/14-15/17, A*2902/04/06 }^{*}\end{array}$ & $\begin{array}{l}\text { A29, A--- } \\
A^{*} 29010101-06, A^{*} ?\end{array}$ \\
\hline $\begin{array}{l}A 1, A 30 \\
A^{*} 0102, A^{*} 3001 / 08\end{array}$ & $\begin{array}{l}\text { A1, A30 } \\
A^{*} 010101-06 / 08-09, A^{*} 3001 / 11\end{array}$ \\
\hline $\begin{array}{l}\text { A2, A29 } \\
\text { A }^{*} 020101-0104 / 03 / 07 / 09 / 11 / 15 N / 201-202 / 22, A^{*} 2902 / 04 / 06\end{array}$ & $\begin{array}{l}\text { A2, A29 } \\
\text { A }^{*} 020101 / 0104-07 / 09-10 / 12-16 / 18-19 / 21-34 / 36-39 / 40-41 / 43 N-47 / 49 / 51-54, A^{*} 29010101-06\end{array}$ \\
\hline $\begin{array}{l}\text { A24, A31 } \\
A^{*} 310102, A^{*} 240301-0302 / 08\end{array}$ & $\begin{array}{l}\text { A24, A31 } \\
A^{*} 310102-02 / 04-06, A^{*} 24020101-0202 / 04-06 / 08-09 N / 11 N-13 / 15-17 / 20-21 / 23 / 25-32 / 34\end{array}$ \\
\hline $\begin{array}{l}\text { A26, A32 } \\
A^{*} 2601 / 05 / 10 / 12 / 15 / 17, A^{*} 3201 / 03 / 05 / 07\end{array}$ & $\begin{array}{l}\text { A32, A--- } \\
A^{*} 3201-03 / 06, A^{*} ?\end{array}$ \\
\hline $\begin{array}{l}\text { A1, A26 } \\
A^{*} 010101-0102 / 03-04 N / 09, A^{*} 2601-02 / 05 / 10 / 12 N / 15 / 17\end{array}$ & $\begin{array}{l}\text { A1, A26 } \\
A^{*} 010101-09, A^{*} 2603 / 05-06 / 16\end{array}$ \\
\hline $\begin{array}{l}\text { A30, A36 } \\
A^{*} 3002 / 09-10, A^{*} 3601\end{array}$ & $\begin{array}{l}\text { A30, A36 } \\
A^{*} 3001-06 / 09-11, A^{*} 3601\end{array}$ \\
\hline $\begin{array}{l}\text { A1, A24 } \\
A^{*} 010101-06 / 09, A^{*} 2402101 / 02102 L / 0202 / 05 / 09 N / 11 N\end{array}$ & $\begin{array}{l}\text { A1, A24 } \\
\text { A }^{*} 010101-06 / 08-09, A^{*} 24020101-022 / 04-05 / 08-09 N / 11 N-13 / 15-17 / 20-21 / 23 / 25-31 / 32 / 34\end{array}$ \\
\hline $\begin{array}{l}\text { A2, A23 } \\
\text { A*020101-0104/0108/06-07/09/15N/18/201-21/24/26/29-30/32N-33/42-43N/46/53N/55/58, } A^{*} 2301 / 05-08 N\end{array}$ & $\begin{array}{l}\text { A2, A23 } \\
\text { A }^{*} 020101 / 0104-07 / 09-10 / 12-16 / 18 / 21-34 / 36-38 / 40-41 / 43 N-47 / 49 / 51-54, A^{*} 2301 / 03 / 05-08 N\end{array}$ \\
\hline $\begin{array}{l}\mathrm{A} 1, \mathrm{~A} 24 \\
\mathrm{~A}^{*} 010101-012 / 03-04 \mathrm{~N} / 09, \mathrm{~A}^{*} 2402101-102 \mathrm{~L} / 22 / 05 / 08-09 \mathrm{~N} / 11 \mathrm{~N} / 20-21 / 25-26 / 29 / 31-32 / 34 / 36 \mathrm{~N}\end{array}$ & $\begin{array}{l}\text { A1, A24 } \\
\text { A }^{*} 010101-06 / 08-09, A^{*} 24020101-0202 / 04-05 / 09 N / 11 N-13 / 15 / 17 / 20-21 / 23 / 25-30 / 32 / 34\end{array}$ \\
\hline $\begin{array}{l}\text { A1, A2 } \\
\mathrm{A}^{*} 010101-0102 / 03-06 / 09, \mathrm{~A}^{*} 020101-0104 / 0108 / 04 / 07 / 09 / 11-13 / 15 \mathrm{~N} / 19-202 / 22 / 24 / 26-27 / 29-30 / 32 \mathrm{~N}-33 / 36- \\
37 / 42-43 \mathrm{~N} / 45 / 49 / 52-53 \mathrm{~N}\end{array}$ & $\begin{array}{l}\text { A1, A2 } \\
A^{*} 010101-06 / 08-09, A^{*} 020101 / 0104-07 / 09-10 / 12-16 / 18 / 21-34 / 36-38 / 40-41 / 43 N-47 / 49 / 51-54\end{array}$ \\
\hline $\begin{array}{l}A 1, A 31 \\
A^{*} 010101-09, A^{*} 310102 / 02 / 07\end{array}$ & $\begin{array}{l}\text { A1, A31 } \\
A^{*} 010101-06 / 08-09, A^{*} 31012-02 / 04-06\end{array}$ \\
\hline $\begin{array}{l}\text { A11, A11 } \\
\text { A }^{* 110101-0102 / 05 / 07-09 / 12-13}\end{array}$ & $\begin{array}{l}\text { A11, A11 } \\
\text { A*110101-10/12 }^{*}\end{array}$ \\
\hline 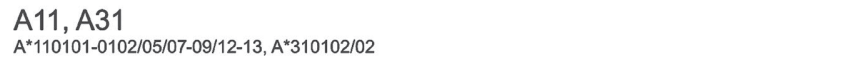 & $\begin{array}{l}\text { A11, A31 } \\
\text { A*110101-09/12, }^{*} 31012-06\end{array}$ \\
\hline $\begin{array}{l}\text { A3, A24 } \\
\text { A }^{*} 030101-0103 / 02 / 06-07, A^{*} 2402101-022 / 05-07 / 09 N / 11 N / 13 / 20-21 / 25-26 / 29 / 32 / 34 / 36 \mathrm{~N}\end{array}$ & $\begin{array}{l}\text { A3, A24 } \\
\text { A }^{*} 030101-4 / 07 / 09, A^{*} 24020101-0202 / 04-06 / 09 N / 11 N-13 / 15 / 17 / 20-21 / 23 / 25-30 / 32 / 34\end{array}$ \\
\hline $\begin{array}{l}\text { A30, A36 } \\
A^{*} 3001-06 / 08-12, A^{*} 3601 / 03\end{array}$ & $\begin{array}{l}\mathrm{A} 30, \mathrm{~A} 36 \\
\mathrm{~A}^{*} 3001 / 11, \mathrm{~A}^{*} 3601\end{array}$ \\
\hline $\begin{array}{l}\text { A1, A2 } \\
\text { A }^{*} 010101-09, A^{*} 020101-0104 / 0108 / 07 / 09 / 15 N / 201-22 / 24 / 26 / 29-30 / 32 N-33 / 42-43 N / 45 / 53 N / 58\end{array}$ & $\begin{array}{l}\text { A1, A2 } \\
\text { A }^{*} 010101-06 / 08-09, A^{*} 020101 / 0104-07 / 09-10 / 12-16 / 18 / 21-34 / 36-38 / 40-41 / 43 N-47 / 49 / 51-54\end{array}$ \\
\hline
\end{tabular}


to weak amplifications. However, the RFLP methodology detected both alleles (allele families) in these two samples, in which the single allele assigned by the kit was also detected by RFLP. Although only 23 individuals were tested, the more than $95 \%$ agreement obtained between the methodologies suggests that the PCR-RFLP technique for HLA-A typing is as sensitive as the commercial kit and shows a high level of reliability. Rare alleles are theoretically distinguishable using this approach since RFLP is based on specific endonucleases that recognize specific DNA sequences, but this could not be confirmed due to the absence of samples carrying these alleles.

In addition, blood samples from 70 randomly chosen individuals were evaluated by the PCR-RFLP methodology to compare their HLA-A distribution with the previously reported distribution within the Brazilian population (13-15). The most frequent HLA-A allele family in Brazil is the A2 group, but representative frequencies also occur for the A1, A3, A24, and A68 groups (13-15). In previous reports of the HLA-A frequency in 3 geographically separate Brazilian subpopulations, Paraná (Southern Brazil), Pernambuco (Northeastern Brazil) and Minas Gerais (Southeastern Brazil), the frequencies were around $8-10 \%$ for HLA-A1, $26-29 \%$ for HLA-A2, 8-14\% for HLA-A3, 10-14\% for HLA-A24, and 5-9\% for HLA-A68. In the present study, the frequencies of these alleles were $10 \%$ for $\mathrm{A} 1,27 \%$ for $\mathrm{A} 2,8.6 \%$ for
A3, $7 \%$ for A24, and $8 \%$ for A68, showing orders of magnitude similar to those of the frequencies reported (13-15). Therefore, the more representative alleles reported for a highly heterogeneous population like the Brazilian one demonstrated a good resolution with the nested PCR-RFLP methodology and a high reliability using the typing procedures reported in the present study.

The alternative methodology for HLA-A polymorphism assignment proposed here was shown to be adequate for low or medium resolution levels. Furthermore, it also permitted the positive discrimination of heterozygous combinations, as do other typing methods $(7,16)$. This may be very useful since the use of commercial kits is relatively expensive for each individual sample. Although the nested PCR-RFLP methodology is more laborious, with a large initial investment in endonucleases, HLA-A typing using this procedure is cheaper since the endonucleases can be used for several analyses, and are at least as sensitive, if not more so, than generic commercial kits.

\section{Acknowledgments}

The authors would like to thank the blood donors, Drs. Elida Benquique Ojopi and Maria Inês de Campos Pardini for helpful suggestions and discussions, Maria Luiza Andanaz Falaguera for blood collection, and Bruna Liboni for invaluable technical help.

\section{References}

1. Doherty PC \& Zinkernagel RM (1975). A biological role for the major histocompatibility antigens. Lancet, 1: 1406-1409.

2. Klein J \& Sato A (2000). The HLA system. First of two parts. New England Journal of Medicine, 343: 702-709.

3. Undlien DE, Lie BA \& Thorsby E (2001). HLA complex genes in type 1 diabetes and other autoimmune diseases. Which genes are involved? Trends in Genetics, 17: 93-100.

4. Robinson J, Waller MJ, Parham P, de Groot N, Bontrop R, Kennedy LJ, Stoehr P \& Marsh SGE (2003). IMGT/HLA and IMGT/MHC: sequence databases for the study of the major histocompatibility complex. Nucleic Acids Research, 31: 311-314.

5. Fleischhauer K, Kernan NA, O'Reilly RJ, Dupont B \& Yang SY (1990). Bone marrow-allograft rejection by $T$ lymphocytes recognizing a single amino acid difference in HLA-B44. New England Journal of Medicine, 323: 1818-1822.

6. Schaffer M \& Olerup O (2001). HLA-AB typing by polymerase-chain reaction with sequence-specific primers: more accurate, less errors, and increased resolution compared to serological typing. Tissue Antigens, 58: 299-307.

7. Mytilineos J, Lempert M, Scherer S, Schwarz V \& Opelz G (1998). 
Comparison of serological and DNA PCR-SSP typing results for HLA-A and HLA-B in 421 Black individuals: a Collaborative Transplant Study report. Human Immunology, 59: 512-517.

8. Chen DF, Seibert I, Chen HY, Herbst-Kiene I, Pastucha LT \& Stangel W (1998). Improvement of HLA class I and class II PCR-SSP typing by using timed-release activity of DNA polymerase. Tissue Antigens, 51: 645-648.

9. Williams F, Meenagh A, Maxwell AP \& Middleton D (1999). Allele resolution of HLA-A using oligonucleotide probes in a two-stage typing strategy. Tissue Antigens, 54: 59-68.

10. Scheltinga SA, Johnston-Dow LA, White CB, van der ZwA, Bakema JE, Rozemuller EH, van den TwJ, Kronick MN \& Tilanus MG (1997). A generic sequencing based typing approach for the identification of HLA-A diversity. Human Immunology, 57: 120-128.

11. Mitsunaga $S$, Tokunaga $K$, Kashiwase $K$, Akaza $T$, Tadokoro K \& Juji $T$ (1998). A nested PCR-RFLP method for high-resolution typing of HLA-A alleles. European Journal of Immunogenetics, 25: 15-27.
12. Marsh SG, Albert ED, Bodmer WF et al. (2002). Nomenclature for factors of the HLA system. Tissue Antigens, 60: 407-464.

13. Middleton D, Williams F, Meenagh A, Daar AS, Gorodezky C, Hammond M, Nascimento E, Briceno I \& Perez MP (2000). Analysis of the distribution of HLA-A alleles in populations from five continents. Human Immunology, 61: 1048-1052.

14. Nigam P, Dellalibera E, Maurício-da-Silva L, Donadi EA \& Silva RS (2004). Polymorphism of HLA class I genes in the Brazilian population from the Northeastern State of Pernambuco corroborates anthropological evidence of its origin. Tissue Antigens, 64: 204-209.

15. Braun-Prado K, Mion ALV, Pereira NF, Culpi L \& Petzl-Erler M (2000). HLA class I polymorphism, as characterized by PCR-SSOP, in a Brazilian exogamic population. Tissue Antigens, 56: 417-427.

16. Moribe $T$, Kaneshige $T$ \& Inoko H (1997). Complete HLA-A DNA typing using the PCR-RFLP method combined with allele group- and sequence-specific amplification. Tissue Antigens, 50: 535-545. 